Vicente de Paula Dias ${ }^{1}$

\title{
AVALIAÇÃO E FUNÇÕES: NO PROCESSO DE ENSINO APRENDIZAGEM PARA A QUALIDADE DA EDUCAÇÃO NA ESCOLA PEQUENO POLEGAR NO MUNICIPIO DE SÃO FELIX DO XINGU-PA, ANO DE 2018.
}

\section{RESUMO}

Este Artigo é uma parte da tese que se encontra em elaboração, com o intuito de focalizar o processo de avaliação no ensino-aprendizagem que a tona à discussão sobre a avaliação, como palco no ambiente escolar e de acordo com as proposta da Lei de Diretrizes de Bases da Educação Nacional n 9394/96 foi sancionada e verificou que apesar do novo direcionamento da Lei de Diretrizes e Bases da Educação Nacional o método tradicional apenas avaliação bimestrais, com o único objetivo de aprovar ou reprovar ainda faz parte do currículo do aluno, a realidade está muito distante que o sistema de avaliação que se pretende alcançar, nesta perspectiva de vivenciar nova fase da educação. Pensa se em avaliação libertadora em inovar a pratica docente com relação a essa temática, não prejudicando o processo de construção do conhecimento assim defende LUCKESI. (2011).

Palavras chaves: Processo de ensino-aprendizagem, avaliação Somativa, avaliação mediadora, Qualidade educacional.

\footnotetext{
${ }^{1}$ Graduado em Licenciatura plena em Pedagogia pela Universidade Vale do Acaraú (UVA). Pós graduado pela FATIN (Faculdade de tecnologia Integrada). E mestre pela faculdade Lusófona de Portugal. E Doutorando pela facultad interamericana de ciências socializes de educação Assunção Paraguai. Este Artigo é parte da tese que se encontra em elaboração.
} 


\section{INTRODUÇÃO}

\section{DESAFIOS E POSSIBILIDADES: DA AVALIAÇÃO PARA O ENSINO}

APRENDIZAGEM

O Artigo aborda o processo de avaliação no ensino aprendizagem e todo processo avaliativo e da investigação e todo trabalho realizado. Os estudos realizados nesta pesquisa são frutos de muita persistência e muita força de vontade que sem sombra $\mathrm{de}^{2}$ dúvida contribuiu para este estudo empírico, que no qual tenho imenso prazer de estar concluindo com êxito, por mais que seja árduo, esse é o motivo para continuar sempre a lutar por uma educação de qualidade e por uma educação mais igualitária e justa para todos.

Hoje como professor da rede municipal de ensino do município de São Félix do Xingu, Estado do Pará, atuando dentro de sala de aula desde 2002 atualmente concursado como professor iniciei minhas atividades na educação ainda com nível médio, com formação em magistério, posteriormente concluir uma licenciatura plena em pedagogia pela Universidade Estadual Vale do Acaraú (UVA) mais tarde pude concluir minha pósgraduação em Ciência da Educação com acesso ao mestrado pela FATIN (Faculdade de tecnologia Integrada) e graça essa especialização estou concluindo não só mais um título de pós graduação no curso de doutorado, como também acumulando mais conhecimento e mais experiência dentro da minha prática pedagógica. Sobretudo em relação à avaliação do ensino-aprendizagem.

Somente na metade do século passado que o debate sobre o exame (aprova) transita em direção aos testes e se finca na expressão avaliação, como assinala BARRIGA (In: ESTEBAM 2001, p.72). Bem recentemente à avaliação ganha uma dimensão mais abrangente, passando a ser referenciada como "avaliação do processo de ensinoaprendizagem." Essa dimensão traz em seu bojo uma nova abordagem epistemológica que orienta não apenas uma nova avaliação, como também uma nova forma de relaciona ser com os demais elementos do processo educativo.

A avaliação tradicional ainda existe como base da pedagogia escolar, por mais que existam professores que tenham como objetivo uma visão transformadora e construtivista, ainda assim quando se depara com o ambiente escolar principalmente escola pública constata-se que infelizmente as metodologias, as estratégias, os recursos, 
as dificuldades ainda são as mesmas. Uma pedagogia pouca inovadora de exames ou provas, onde norteia toda prática de professores entre alunos.

Neste sentido, em busca do autoconhecimento, e de valorização profissional, e pessoal faz se necessário, desenvolver esta pesquisa de campo, partir de estudo de caso, de embasamento teórico em diversos autores que nortearam este trabalho, sobretudo em relação à avaliação ao do processo de ensino-aprendizagem.

Verificou-se que na realidade que a forma como são conduzidos os processos de é conduzido os processos de ensino-aprendizagem no lócus da pesquisa, não condiz com os PCN'S nem o regimento interno da escola, no qual deveria ser contemplado, porém o foco desta pesquisa se restringe basicamente à avaliação no ensino-aprendizagem, temática deste estudo, sobre a avaliação no ensino-aprendizagem.

Nossa pesquisa buscou informações qualitativas e quantitativas referentes a estudos mais recentes e atualizados realizados a respeito da avaliação da aprendizagem escolar no Brasil. Esses dados se mostraram interessantes na medida em que retratam resultados de pesquisas realizadas no interior das escolas brasileiras.

Levando sempre em consideração as experiências vivenciadas no cotidiano dentro da nossa realidade FACULTAD INTERAMERICANA DE CIENCIAS SOCIALES DOUTORADO EM CIENCIAS DE EDUCAÇÃO ASUNSSÃO PARAGUAY

, aonde a globalização e a informatização se tornam o palco da humanidade e tudo que se faz hoje é reflexo da convivência em nossa sociedade, é relacionada à hierarquia de complexo de entendimento social principalmente para a educação dos nossos jovens.

O referido projeto se desenvolveu diante da situação problema que assolava uma determinada escola, portanto houve se uma preocupação em estudar o assunto de caso que era a inquietação da problemática que era o processo de avaliação no ensino aprendizagem, esse tema que bastante complexo, que vai de encontro aos paradigmas e metodológicos que envolvem os profissionais da educação de modo geral para essa questão a ser amenizada de forma cientifica iniciou a pesquisa de campo com ênfase no assunto e com respaldo teórico no sentido de proporcionar maior credibilidade a pesquisa.

Neste contexto acredita-se que infelizmente os nossos profissionais que atuam em sala de aula ainda deixam a desejar ou simplesmente, não conseguem engajar suas práticas de avaliação de maneira coerente e satisfatório sobre o processo de ensinoaprendizagem. O homem é avaliado desde que nasce, das mais diversificadas formas e de acordo com os mais variados objetivos e, assim, a avaliação vai se tornando a cada dia 
um meio que possibilita contemplar o trabalho do professor para orientar a compreensão do presente e a delimitação do futuro.

\section{ESTUDO DA ARTE}

\section{REVISÃO DA LITERATURA EM AVALIAÇÃO NO ENSINO- APRENDIZAGEM}

Este estudo aborda à avaliação da aprendizagem que teve como fundamentação teórica em vários outros em artigos, teses, dissertações, TCC, revistas científicas e outros, para fazer a revisão da literatura e posteriormente o estado da arte que sem dúvida norteou a construção desse estudo.

Iniciou se recorrendo a sites de algumas universidades brasileiras em busca do que foi publicado durante os últimos anos sobre avaliação no ensino aprendizagem para uma ideia o que enfatiza a respeito da avaliação no Brasil nos últimos anos.

$\mathrm{Na}$ trajetória da humanidade, os homens saíram das cavernas, organizaram-se em grupos e passaram da coleta á produção de bens para sua sobrevivência. Os fenômenos começaram a ser associados a mitos e a deuses. Os homens passaram a conviver em cidades e novas explicações vão surgindo para dar conta da complexo que o mundo contém.

Por meio do questionamento: Quais são os meios que se pretende buscar para melhorar a qualidade da avaliação feita pelos docentes no espaço escolar e suas contribuições, do ensino aprendizagem dos alunos de forma significativa?

$\mathrm{O}$ que se pretende é investigar através do objeto de pesquisas as condições e melhorias metodológicas para se trabalhar avaliação com ênfase e total desenvolvimento educacional, que se agregue juntamente com a teoria e a prática do educador juntamente com toda equipe técnica e pedagógica, partimos dos seguintes questionamentos:

- Quais são as propostas dos professores a serem desenvolvidas em prol da avaliação de seus alunos?

- Como ajudar os professores nas propostas de avaliar os alunos em todo o âmbito escolar na qualidade do conhecimento?

- Quais as concepções dos professores e pais sobre a avaliação e suas relações com aprendizagem dos discentes?

- Como Compreender a filosofia de avaliação estabelecida pelos docentes no minúsculo contexto escolar? 
- Será que os professores estão realmente preparados para se fazer uma avaliação que venha satisfazer a sua clientela com qualidade?

Para dar continuidade neste trabalho buscaram-se informações em autores com publicações atualizadas para esta pesquisa, na qual dará suporte de grande relevância confiável ao trabalho que hora se inicia, juntamente com grandes teóricos, que fazem jus a discussão no referencial da pesquisa da avaliação ensino-aprendizagem, esses dados mostram o percurso da avaliação no ensino aprendizagem no Brasil e também buscou-se informações no âmbito da avaliação educacional e sua evolução.

A avaliação do trabalho docente exige transparência por parte de quem se atribui a responsabilidade de estabelecer referentes indicativos da qualidade desejada e, sob este aspecto, é necessário assumir uma postura radical exigindo conhecer, certamente o ensino e a aprendizagem que necessita ser incluída desde logo nos processos de formação docente para promover mudanças na cultura escolar, sobretudo capacitar o aluno para exercer a sua cidadania.

A autora afirma ainda que o primeiro passo seria um posicionamento claro e explícito sobre o tipo de sociedade e de cidadão que se pretende formar, LUCKESI diz que.

Segundo a autor o momento de avaliar não deve ser isolado de todo processo educacional e deve acontecer de acordo com o desenvolvimento do aluno em sala de aula. Cada ato de ensinar e aprender consiste em tentar realizar esses objetivos, o ato de avaliar consiste em verificar se eles estão sendo realmente atingidos.

A avaliação assume uma dimensão orientadora, cooperativa e interativa, onde os resultados obtidos no decorrer do trabalho conjunto do professor e dos alunos são comparados com os objetivos propostos a fim de constatar o progresso as dificuldades e também reorientar o trabalho docente bem como e a construção de projetos pedagógicos.

Gonçalves e LARCHERT (2012) autoras da dissertação Avaliação da aprendizagem dizem que a avaliação supera a nota, é um processo diagnóstico, interativo, como dialógico do ensino e das aprendizagens a serviço da escola bem como objetivo a aprendizagem, onde o exame está voltado para a promoção do estudante a série subsequente de escolaridade que resume no conhecimento do aluno. Ele precisa dela, não importa se ela expressa ou não uma aprendizagem satisfatória, ele quer a nota, é a média que domina tudo e é em função dela que se vive na prática escolar LUCKESI (2002), onde os testes foram os instrumentos utilizados para a mensuração da inteligência dos educandos. 
Segundo GONÇALVES e LARCHERT (2012) a primeira escala de inteligência foi construída pelo pedagogo para medir o grau de aprendizado dos alunos e foi com o psicólogo francês (1996) que a avaliação assume o papel de medir a capacidade e a inteligência dos alunos com dificuldade de aprendizagem na escola da rede pública e privada.

Por causa da maneira autoritária que a avaliação tem sido aplicada no interior das escolas, consequência da sua concepção e história, é urgente o resgate da avaliação formativa e processual.

WEBER (2007) autora da dissertação Avaliação da aprendizagem escolar: prática em novas perspectivas assume uma nova concepção de inovação para a prática educativa no texto educacional, sempre procurando adaptar-se aos novos modelos e padrões de avaliar o educando. Com o intuito de fazer o que há de melhor em questão de avaliação não existe uma regra específica para avaliar apenas a interdisciplinaridade no ensino da aprendizagem dos alunos, WEBER esclarece que.

Em nossa prática procuramos mudar e melhorar a metodologia de trabalho, juntamente com as interações em sala de aula. Este foi o primeiro passo para melhorar o desenvolvimento profissional mais adequado ás mudanças que estão ocorrendo no mundo atual, pois acreditamos que a escola deve refletir o que a sociedade tem que ser desde que atenda suas necessidades das pessoas e contribua para ajudar no crescimento intelectual, social e econômico. (WEBER, 2007, p.08).

Segundo a autora, a avaliação da aprendizagem deve ser feita diariamente em conjunto com os professores, valorizando o que o aluno aprendeu durante o conteúdo ministrado e analisando seu desenvolvimento intelectual. Dessa forma o objetivo da escola é oferecer o ensino de qualidade e eficaz, tudo isso deve estar atrelado em conjunto com o corpo docente, para que essa interação possa favorecer uma educação de qualidade para todos.

Avaliação da aprendizagem pode valer-se de vários instrumentos e dentre eles se destaca com grande relevância a prova, testes, exames, atividades coletivas e individuais.

O contexto da avaliação está pautado no modelo do paradigma que coloca no discurso o diálogo entre professor e aluno baseado na forma de trabalho metodológico e no entendimento de ambos para o conhecimento sistematizado. A meta da avaliação é colocada em evidência e envolve um conjunto de reflexões críticas sobre o aspecto avaliativo.

A necessidade de avaliar os alunos em sua dimensão é especificamente a aprendizagem do educando está direcionada a aprendizagem do educando, das 
instituições nas organizações nos sistemas e projetos nas políticas públicas, sendo o tipo de avaliação que mobiliza educadores e discentes na prática docente no seu cotidiano.

LEILA E DAVID (2008) autoras do artigo Repensando a prática avaliativa na formação e na atuação do professor defende a avaliação como o encanto de avaliar e selecionar, mas para possibilitar a todos os alunos o conhecimento crítico e criativo, instrumento necessário quando se tem como compromisso não a conformação à realidade, mas sua transformação, servindo assim a avaliação à inclusão e não à exclusão do aluno no ensino-aprendizagem. A avaliação vai deixando de ser a grande vilã da escola brasileira para ser pensada como uma grande janela pela qual se entra para alterar as ações e relações escolares.

Dessa forma, destaca-se a importância do envolvimento do aluno para modificar o papel tradicional ocupado pela avaliação da aprendizagem e discutira avaliação é relativo a posturas e concepções vivenciadas, com isso não há um acordo conceitual único dito de outra forma, mudar as práticas avaliativas implicam modificar o papel do aluno, transformando-o em interlocutor no seu processo de aprendizagem e na sua relação com o professor.

MELO E BASTAM (2012) autores do artigo Avaliação escolar como processo de construção de conhecimento defende o processo de avaliação como sendo necessário redimensionar a prática de avaliação no contexto escolar, pois não é acabando com a prova que se melhora o processo de avaliação da aprendizagem mas como atividade proposta pela instituição que é usada como instrumento de avaliação, para ANTUNES (2002) o processo de avaliação da aprendizagem consiste essencialmente em determinar se os objetivos educacionais estão sendo realmente alcançados pelo programa do currículo e do ensino como ferramenta exclusiva do professor.

Ser professor tradicional é mais fácil do que na escola nova, perspectiva, pois para o professor tradicional cabe somente a ele saber o conteúdo programático, o que irá apresentar aos alunos, transmitir em aula o que está previsto e escrito nos livros, depois cobrar nas provas da mesma forma como ensino de hoje, segundo HOFFMANN (2005), a avaliação informa ao professor o que foi aprendido pelo aluno. VASCONCELOS diz que.

Seria importante lembrar que a mudança de mentalidade se dá pela mudança de prática. Se o discurso resolvesse, não teríamos mais problemas com a avaliação, pois qual o professor não sabe que "a avaliação é um processo contínuo que visa um diagnóstico...", ou ainda, que já não disse " $n$ " vezes para seus alunos que o importante não é a nota, mas sim a aprendizagem. (VASCONCELOS, 1998, p. 34). 
VASCONCELOS (1998) diz que o objetivo de trabalhar para a construção do saber engajado diz respeito a avaliação na educação, mas levando em conta a filosofia no ensino de cada instituição a aprendizagem para o teórico, é um momento onde se busca as melhores condições de ensino para o aluno.

ROCHA (2008) no artigo Avaliação-processo em construção diz que é a avaliação que vai permitir que se façam sugestões, encaminhamentos e também a tomada de decisões coerentes à medida que se limita constatar uma realidade, a obter dados e informações. A avaliação não pode se resumir apenas a conceito de forma estatística como atribuição de notas que servirão para tomadas de decisões referentes ao ensino aprendizagem.

Diante disso, é imprescindível que os professores tenham clareza à definição de Avaliação, os tipos que precisam utilizar em cada situação, são necessários que o professores estejam convictos com a definição de avaliação, os tipos que precisam utilizar em cada situação. A avaliação da aprendizagem oferece suporte para a tomada de decisão e a melhoria da qualidade de ensino através da análise das ações em desenvolvimento e a necessidade de mudanças constantes.

RIBEIRO (2010) autora do trabalho de conclusão de curso Avaliação da aprendizagem no ensino fundamental: na prática avaliativa tem como questionamento a respeito da avaliação como um processo isolado de todo caminho percorrido pelo aluno na construção do conhecimento sistematizado, deste então a avaliação nas escolas brasileiras continua sendo realizadas por meio de provas e exames para verificar o aproveitamento dos alunos nas matérias escolares e para o professor se certificar que o aluno conseguiu aprender o que lhe foi ensinado.

Dessa forma, os professores cristalizaram em nossas escolas a prática de provas e exames como um dos recursos para classificar os educandos e selecioná-los.

Os alunos neste processo são tratados pela escola de maneira diferenciada, preocupando-se com os princípios da individualidade e da competitividade, para LUCKESI. (2003) as práticas escolares cotidianas explicitam a impossibilidade de reduzir a avaliação a um conjunto de momentos estanques que costuram fragmentos do processo de ensino e aprendizagem, principalmente quando atuamos na escola pública. Como já mencionamos a avaliação sempre foi uma atividade de controle, que visava selecionar, neste sentido o prazer de aprender cada vez mais.

MAFFASIOLI e VERLE (2009) no artigo Avaliação da aprendizagem no PROEJA do IFRS-BG: uma abordagem feita a partir de seus sujeitos esclarece que a 
avaliação é vista como um dos momentos mais significativos do processo de ensino e de aprendizagem, sendo um processo muito importante em termos de educação e que a avaliação vem sendo cada vez mais reformulada.

O modelo da escola progressista libertadora traz uma proposta de avaliação em que procura olhar cada aluno de forma diferente e faz se aproveitar tudo de bom que o aluno pode oferecer na sua bagagem cultural em conhecimento sistematizado.

A fim de saber quais as dificuldades de cada um é necessário fazer um diagnóstico que poderá auxiliá-lo por meio das diversas formas de definir a avaliação.

ANTUNES (2002) diz que a avaliação é muitas vezes usada como uma medida, mas sabe-se que o ato de avaliar é muito mais do que simplesmente medir. Tanto a avaliação quanto o processo de ensino vem mudando no decorrer do tempo, mudar é preciso ainda que permanecer com se esta seja sempre mais fácil, avaliar onde o trabalho do docente é plenamente relevante é imprescindível ainda que medir seja extremamente confortável para o professor.

$\mathrm{Na}$ escola tradicional tínhamos um ensino em que o professor era um mero transmissor do conhecimento, onde ele levava o conteúdo ao aluno e este por sua vez precisava entendê-lo e mostrar através de uma prova o que tinha aprendido, seguindo a corrente informação. Em uma concepção dialética de avaliação o professor não está preocupado em transmitir conhecimento, mas sim em proporcionar aprendizagens significativas aos seus alunos.

A avaliação é um julgamento de valor sobre manifestações relevantes da realidade, tendo em vista uma tomada de decisão, ou seja, avaliar implica a emissão de julgamentos de valores, a partir de dados coletados, visando a uma tomada de decisão. Para LUCKESI (2003) este modelo produziu três pedagogias distintas, mas com um objetivo em comum que é manutenção das condições sociais, sendo que a pedagogia tradicional a avaliação faz parte do processo da mediação pedagógica do professor envolve também aspectos afetivos e não se restringe apenas à dimensão cognitiva do educando.

HOFFMANN (2009) diz que a avaliação mediadora é a dinamização das oportunidades de ação-reflexão, acompanhamento permanente por parte do professor, é uma prática que desafia o aluno.

A avaliação mediadora é aquela que ilumina e assume o seu verdadeiro papel quando trata do erro, nessa concepção de avaliação o erro é tratado como uma possibilidade de acerto. 
SORATO BUSS e BONIFÁCIO no artigo A avaliação do ensino aprendizagem no curso de ciências contábeis da UNESCO ressaltam que a avaliação deve destacar, ainda, o interesse do aluno em aprender novos conteúdos e técnicas diferenciadas de saber que está ligada o seu interesse pessoal e o compromisso com a escola de aprender o que foi ensinado e estimular a sua capacidade de absorção de conteúdo, para o aluno é entendido como a essência da função educacional, e é imperativa a perfeita caracterização de suas necessidades de aprendizagem.

ESTEBAN (2003) diz que no papel desempenhado pelo professor no processo de ensino e aprendizagem nota-se que a percepção que o aluno deve possuir frente às atividades desenvolvidas pelo educador consiste em desejar aprender. O papel do professor no processo de ensino e aprendizagem deve ser auxiliar o aluno a aprender, propiciando os meios necessários para que se busque o conhecimento, atuando como um mediador.

\section{TEMA}

A educação e a avaliação fazem parte historicamente do processo de ensinoaprendizagem, onde os objetivos educacionais referentes à formação do aluno são determinados e onde também verifica se os objetivos estão sendo atingidos, pois a escola é a transformação social são os indicadores que direcionam as recomendações que propõe trabalhar o caráter formativo da avaliação no âmbito escolar.

A esse respeito pode se verificar os pressupostos presente nas práticas educativas das escolas brasileiras a partir de diversos autores, entre eles: os jesuítas, comênio. (15921670), rousseau (1712-1778), herbet (1776-1841), dewcy(1859-1952) sknner (19041980) freire (1921-1997) piaget1896-1980) vygotsky (1896-1934) e saul (2006). É valido ressaltar que a escolha por esses pensadores aconteceu em razão de uma organização didática que favorecesse a discussão sobre a compreensão dos métodos de ensino e de aprendizagem num movimento histórico.

Este trabalho está organizados, em capítulos o mesmo pretende elucidar um diagnóstico do tema enunciado no título, passando pela apresentação do problema, uma pequena parte da revisão teórica e por fim, a explanação do resumo de cada capítulo os objetivos e questões de pesquisa que embasaram e deram suporte teórico ao estudo.

Aborda sobre os referenciais teóricos e os conceitos históricos, além de analisar um breve estudo realizado a partir de pesquisas nos últimos cinco anos no Brasil, que nos permitiram analisar o estado da arte, onde se buscou informações para trazer aos leitores 
uma ideia geral a respeito da avaliação escolar e do nível de conhecimento nessa área, embasados principalmente nas pesquisas mais recentes a respeito do assunto.

Para LUCKESI (2003) esclarece que a tradição dos exames escolares que conhecemos hoje em nossas escolas foi sistematizada nos séculos XVI e XVII com as configurações da atividade pedagógica produzidas pelos padres JESUÍTAS Século XVI e pelo bispo protestante John Amós COMÊNIO (fim do Século /XVI e primeira metade do XVII). Certamente que existiam exames antes desse período, pois existem registros de exames utilizados na China em torno de três mil anos AC (antes de Cristo) para selecionar homens para o exército, porém, exames escolares como são praticados hoje em nossas escolas, foi sistematizado com advento da modernidade e sua consequência na prática educativa.

Futuras gerações para que atuem e desenvolvam suas habilidades adquiridas no dia adia e na busca desses novos sentidos e orientações em propostas de autores e atuais diretrizes nacionais que organizem, revisam estruturas e estratégias para que venha abordar a questão da avaliação e práticas educativas tais como a LDB, PCN'S e nas diretorias para professores.

A palavra avaliar origina-se do latim valere que significa: ser forte, ter valor. No senso comum avaliar é empregado no sentido de atribuir valor a alguém ou a um objeto, assim a avaliação permite diversos significados, tais como: verificar, calcular, medir, apreciar, classificar, diagnosticar, entre outros.

ESTEBAN (2003) afirma que o texto traz à tona a discussão sobre a avaliação escolar, e por ser um tema polêmico, à avaliação do ensino-aprendizagem mostra quais novos sentidos e orientações que vêm sendo sugeridas para a sua transformação prática, de modo que constitui instrumento educacional seja inclusivo, formativo e pedagógico, dessa forma vai de encontro aos novos sentidos e orientações em propostas de alguns pensadores atuais que discutem a questão e nas diretrizes nacionais atuais que organizam e revisam estruturas, estratégias e práticas educativas.

Na opinião do autor avaliação deixa de ser modelo padrão para se trabalhar de forma diferenciada, onde cada aluno é único e por isso aprende de forma bem diferente. A avaliação oferece ao professor caminhos a serem seguidos de acordo com os resultados obtidos no processo de avaliação dos alunos. Dentro desses aspectos o professor assume o papel de transformador para garantir o educando melhor condições de aprendizagem. LUCKESI (2011) defende que avaliação da aprendizagem, levando em consideração as 
práticas vivenciadas pelos professores é um recurso pedagógico capaz de auxiliar o professor na sua prática educacional. A avaliação é algo que deve ser consistente e eficaz no processo de ensino-aprendizagem. Julgamos, atribuímos valor a tudo sobre o qual não somos indiferentes, fazemos escolhas, opinamos sobre coisas, acontecimentos, pessoas, a partir de critérios por nós adotados. Também somos julgados pelas pessoas com as quais convivemos no dia a dia, pelos professores que acompanham nossa atividade profissional, entre outros.

A avaliação é um instrumento de grande necessidade ao homem no seu processo de construção e dos resultados que planejou obter, bem como para orientação de suas ações. Isto nos leva a refletir sobre algumas questões do fazer da avaliação. São elas: para que avaliar? O que é avaliar? O que avaliar? Quando avaliar? Como avaliar e o que fazer com os resultados da avaliação? Esses questionamentos representam as dúvidas dos professores no momento de seu trabalho pedagógico. A reflexão sobre essas perguntas colabora para a autonomia didática dos professores

LIBÂNEO (1994) diz que os educadores devem ter em mente os limites de suas utilizações, pois nem todos os resultados de ensino podem ser medidos ou averiguados através de testes. Se essa perspectiva, de um lado, retira dos professores a capacidade de serem autores isolados de transformações, de outro, confere-lhes autoridade pública para realizá-las LUCKESI (2003, p.132) ressalta que "toda ação necessita de um executor, e a execução de ação efetiva requer um executor plenamente consciente do que está fazendo e onde deseja chegar com sua ação" com isso o efeito, a capacidade emancipatória e transformadora dos professores e das escolas como esfera democrática e social.

No próximo tópico abordaremos o estado da arte e a revisão da literatura sobre o processo de avaliação no ensino aprendizagem por meio dos trabalhos que foram publicados nos últimos três anos e como andam os processos de avaliação no ensino-aprendizagem

\section{PLANEJAMENTO DO PROBLEMA}

Diante da problemática existente o que deve ser feito pelas políticas públicas em prol do ensino aprendizagens no processo educacional da escola municipal de ensino fundamental pequeno polegar no município de São Felix do Xingu PA neste ano em curso de 2018? Implantar projetos voltados ao sistema de avaliação, explorar o potencial dos educandos, com incentivo boa pratica, de estudos modificar o sistema de avaliação mobilizando toda comunidade escolar através de política públicas, incluindo no planejamento proposta de avaliação que seja prazerosa e agradável sem punição, buscando referencial teórico em grandes clássicos como JUSSARA HOFMAMM, 
FELIPE PERRENOUD, CELSON ANTUNES e outros. Sabe se da grande dificuldade que ora nos deparamos falta de motivação por parte de nossos discentes, sem interesse de estudar, então propõe se desenvolver projetos com parcerias com a direção da escola coordenador, professores para minimizar a problemática que o processo de avaliação na escola de ensino fundamental pequeno polegar em são Felix do Xingu PA

\section{PERGUNTAS DA INVESTIGAÇÃO}

'Como ajudar os professores nas propostas de avaliar, os alunos em todo o âmbito escolar, na qualidade do conhecimento?

Quais as concepções dos professores, e pais, sobre a avaliação e suas relações com aprendizagem dos discentes?

Como Compreender a filosofia de avaliação estabelecida pelos docentes no contexto escolar?

Será que os professores estão realmente preparados para se fazer uma avaliação que venha satisfazer a sua clientela com qualidade?

\section{CONTEXTUALIZACAO DO PROBLEMA}

De acordo com a pesquisa realizada buscou se uma proposta de concepção investigativa de cunho social apesar do problema existente que diz a respeito do processo de avaliação, sem dúvida isso requer tratamento especial no âmbito escolar, uma vez que não é um caso isolado e nem é deficiência de gestão e sim, uma problemática do meio que nossos alunos estão inseridos. Por que o número de alunos reprovados e considerável? Para que o problema seja minimizado é preciso unirmos entre comunidades escolares e poder público? Dessa forma pretende se buscar alternativas pedagógicas e práticas inovadoras, que sensibilize e motive cada vez mais, o interesse dos alunos da escola municipal de ensino fundamental pequeno polegar, Com muita determinação e persistência, junto com o corpo docente e discente, fara se projetos educacionais voltado para o processo de avaliação que venha contemplar toda clientela escolar.

\section{JUSTIFICATIVA}

Nesse contexto a pesquisa se propõem a estudar o tema, da avaliação no ensino aprendizagem na escola municipal de ensino fundamental pequeno polegar no município de são Felix do Xingu PA, a qual tem sido motivo de estudo Nesse contexto a pesquisa se propõe a estudar à temática a qual tem recebido destaque nos meios de deficiência escola onde se tem o problema de alunos com números considerável retidos, isso é muito preocupante então e motivo de inquietação por parte do corpo docente e na comunidade 
científica após aprovação da Lei de Diretrizes e Bases da Educação Nacional - LDB (Lei Federal n. 9.394).

Com essa lei, a educação brasileira passa a ser orientada pelos PCN, os quais propõem, dentre seus temas transversais, a "avaliação" e, nesta seção, a contribui como caminho possível para o enfrentamento da avaliação atual. Ainda segundo a análise do referido autor, com o passar do tempo se superou a questão do ensino aprendizagem e toda estrutura curricular e a forma de perceber a avaliação, como processo como um todo, Os estudos realizados nesta pesquisa são frutos de muita persistência e força de vontade que sem sombra de dúvida contribuiu para este estudo empírico, que no qual tenho imenso prazer de expor e concluir com êxito, por mais que seja árduo esse é o motivo para continuar sempre lutar por uma educação de qualidade e por uma educação mais igualitária e justa para todos.

Hoje como professor da rede municipal de ensino do município de São Félix do Xingu, Estado do Pará, atuando dentro de sala de aula desde 2002 atualmente concursado como professor iniciei minhas atividades na educação básica ainda com nível médio, com formação em magistério, posteriormente concluir uma licenciatura plena em pedagogia pela Universidade Estadual Vale do Acaraú (UVA) mais tarde pude concluir minha pós-graduação em Ciência da Educação com acesso ao mestrado pela FATIN (Faculdade de tecnologia Integrada) e graça essa especialização E dando continuidade o conhecimento avançado cada vez, caminhando rumo ao doutorado com mais entusiasmado com esse trabalho tendo a oportunidade de buscar mais entendimento nos avanços da pesquisa que sem dúvida contribuirá para mais um título de doutor em ciência da educação que contribuirá no meu crescimento profissional estou concluindo não só mais um título, como também acumulando mais conhecimento e mais experiência dentro da minha prática pedagógica. Sobretudo em relação à avaliação do ensino-aprendizagem.

Temo o festejo da Santa N ${ }^{a}$ Senhora das Mercês. No mês de abril é comemorada a festa indígena que conta com índios de várias etnias. Temos várias outras festas como: festas juninas, veraneio, olimpíadas, e a festa do padroeiro Santo São Felix que é comemorada dia 21 de novembro.

A pesquisa de campo foi realizada na Escola Municipal de Ensino Fundamental e Infantil 'Pequena Polegar' essa escola foi fundada em 03/03/1990 está localizada no distrito de Ladeira Vermelha, a aproximadamente $140 \mathrm{~km}$ de sua sede, São Felix do Xingu - PA. É uma escola de médio porte, com 09 salas de aula, laboratório de informática, com cinco computadores adquiridos do Proinfo.(Programa Nacional de Informática na 
Educação)- programa do governo federal A escola possui 01 sala de professores com banheiro, 01 cantina, 01 biblioteca 04 . Banheiros dos alunos sendo 02 masculinos e 02 femininos, 01 secretaria com banheiro. Entende-se que a pesquisa será objetivada em lócus na Escola Municipal de Ensino Fundamental Pequeno Polegar, onde a mesma está localizada na zona rural, essa entidade foi fundada com o objetivo de atender toda a sua clientela apesar de ser de médio porte, atende a necessidade da comunidade local, com propósito de melhorar a qualidade do ensino desta localidade.

Somente na metade do século passado que o debate sobre o exame (a prova) transita em direção aos testes e se fica na expressão avaliação, como assinala Barriga (In: ESTEBAM 2003, p.72). Bem recentemente à avaliação ganha uma dimensão mais abrangente, passando a ser referenciada como "avaliação do processo de ensinoaprendizagem." Essa dimensão traz em seu bojo uma nova abordagem epistemológica que orienta não apenas uma nova avaliação, como também uma nova forma de relaciona ser com os demais elementos do processo educativo.

A avaliação tradicional ainda existe como base da pedagogia escolar, por mais que existam professores que tenham como objetivo uma visão transformadora e construtivista, ainda assim quando se depara com o ambiente escolar principalmente escola pública constata-se que infelizmente as metodologias, as estratégias, os recursos, as dificuldades ainda são as mesmas. Uma pedagogia pouca inovadora de exames ou provas, onde norteia toda prática de professores e alunos. Neste sentido, em busca do autoconhecimento, e de valorização profissional, e pessoal faz se necessário, desenvolver esta pesquisa de campo, partir de estudo de caso, de embasamento teórico em diversos Autores que nortearam este trabalho, sobretudo em relação à avaliação ao do processo de ensino-aprendizagem.

\section{ANÁLISE DOS REGISTROS INDIVIDUAIS DE APRENDIZAGEM DOS EDUCANDO NO ANO DE 2017.}

Acredita-se que boa parte desses alunos é fruto da nossa sociedade capitalista onde tem família desestruturada, pais separados ou sem condição financeira que às vezes a renda não atinge um salário digno para a família sobreviver, então essas questões reflete na educação dos filhos e mesmo indiretamente os alunos são afetados.

TABELA 06 - RELATÓRIOS BIMESTRAIS-2018

\begin{tabular}{|l|l|l|}
\hline UNIDADE CATEGORIAL & UNIDADE DISCURSIVA & $\begin{array}{l}\text { QUANT. } \\
\text { ALUNOS }\end{array}$ \\
\hline $\begin{array}{l}\text { Domínio da língua } \\
\text { Portuguesa / matemática. }\end{array}$ & $\begin{array}{l}\text { Possui Conhecimento } \\
\text { Alfabético }\end{array}$ & 20 \\
\hline
\end{tabular}




\begin{tabular}{|l|l|l|}
\hline & & 10 \\
\hline Leitura & Lê Fluentemente & 07 \\
\hline Leitura & Lê com Dificuldade & 05 \\
\hline Leitura & Não Lê & 08 \\
\hline Domínio da Escrita & Dificuldade com a Escrita & 08 \\
\hline Conhecimentos matemáticos & Dificuldades em Cálculos & 31 \\
\hline Conhecimentos matemáticos & Domina cálculos matemáticos & 16 \\
\hline Conhecimentos essenciais & $\begin{array}{l}\text { Não Domina Conhecimento da } \\
\text { Série atual }\end{array}$ & 16 \\
\hline
\end{tabular}

FONTE: Pesquisa de Campo (Set/2018)

Em relação a aprendizagem o que se percebe que esses alunos vão passando de série para outra sem condições de adequadas de conhecimento e domínio de conteúdo, ou seja, são incapazes de ler corretamente e interpretar o que leu isso realmente é preocupante com o futuro dessas crianças, que tipo de cidadãos estaremos formando para o futuro do país?

Dentro da nossa realidade, hoje, nossos alunos a maioria não está interessada em estudar e sim estão preocupados em "enrolar o tempo" e não fazer quase nada na sala de aula, não se sabe o que fazer diante dessa situação que os nossos alunos cada vez mais estão desmotivados para estudar, segundo relatos da secretária que diz que uma boa parte dos alunos vai para a escola sem vontade de estudar, empurrados pelos pais ou somente para garantir a frequência da bolsa família, na realidade são pessoas de baixa renda que precisa desse auxílio para ajudar em suas despesas.com isso gera problema que o filho nem estuda e não ajudar seu pai ou sua mãe em alguma atividade em casa, então acaba dando trabalho para seus pais, brincam na hora das aulas, conversa paralela durante a aula, não prestam atenção nas aulas então isso é um fator determinante para o fracasso escola, foge da escola uma vez que a escola não é murada

\section{ANÁLISE DOS REGISTROS INDIVIDUAIS DE DESENVOLVIMENTO E APRENDIZAGEM DOS EDUCANDOS}

Foram analisados os documentos relatórios, registros individuais dos alunos observando o grau de conhecimentos desses alunos no ano de 2017 para melhor entender os dados da pesquisa coletados através das informações dos professores, dessas turmas e também registros dos diários de classe que comprovam os rendimentos dos mesmos no referido ano em curso. 
Foi considerado imprescindível a representação de tais dados que aqui quantificados, por traduzir a situação das duas turmas analisadas por meio da análise dos relatórios, os alunos do $5^{\circ}$ ano mencionado dessa unidade de ensino através das categoriais da aprendizagem apresentada.

A tabela a seguir demonstra as habilidades e competências das turmas do $5^{\circ}$ ano do ano em curso 2018

TABELA 03 - RELATÓRIOS BIMESTRAIS-2018
\begin{tabular}{|l|l|l|}
\hline UNIDADE CATEGORIAL & UNIDADE DISCURSIVA & $\begin{array}{l}\text { QUANT. } \\
\text { ALUNOS }\end{array}$ \\
\hline $\begin{array}{l}\text { Domínio da língua Portuguesa } \\
\text { matemática. }\end{array}$ & Possui Conhecimento Alfabético & 19 \\
\hline Leitura & Lê Fluentemente & 10 \\
\hline Leitura & Lê com Dificuldade & 18 \\
\hline Leitura & Não Lê & 12 \\
\hline Domínio da Escrita & Dificuldade com a Escrita & 20 \\
\hline Conhecimentos matemáticos & Dificuldades em Cálculos & 21 \\
\hline Conhecimentos essenciais & $\begin{array}{l}\text { Não Domina Conhecimento da } \\
\text { Série atual }\end{array}$ & 05 \\
\hline
\end{tabular}

FONTE: Pesquisa de Campo (Set/2018)

Os sujeitos participantes da pesquisa, nas turmas, totalizam 105 alunos, sendo que para sigilo da identidade dos alunos foram preservados de acordo com a ECA (Estatuto da Criança e do Adolescente) por isso dividiu-se em classificação alfabética, ou seja, cada aluno será representado por uma letra do alfabeto.

Após instrumentalizarmos e tabulamos dos dados, constatados que o número de alunos reprovados e que não dominam a língua portuguesa também apresentam dificuldades na resolução de problemas matemáticos, de forma que fica evidente que esses alunos estão chegando ao $6^{\circ}$ ano do Ensino Fundamental com déficit de aprendizagem em relação às séries anteriores e, em virtude disso, não conseguem um bom desempenho na série em que se está cursando De acordo com a pesquisa feita com os alunos foi perguntado o seguinte: Como você gostaria de ser avaliado nos conteúdos ministrados? Do universo da pesquisa dos 105 alunos pesquisados 57\% responderam que preferem ser avaliado por trabalho ou atividades em grupos, $15 \%$ dos pesquisados gostaria de ser avaliado com avaliação continua, 14\% dos pesquisados diz que gostaria de será avaliados por prova escrita, outros $14 \%$ dos pesquisados responderam que preferem ser avaliada por auto avaliação. 
Gráfico 01- Como você gostaria de ser avaliado nos conteúdos ministrados?

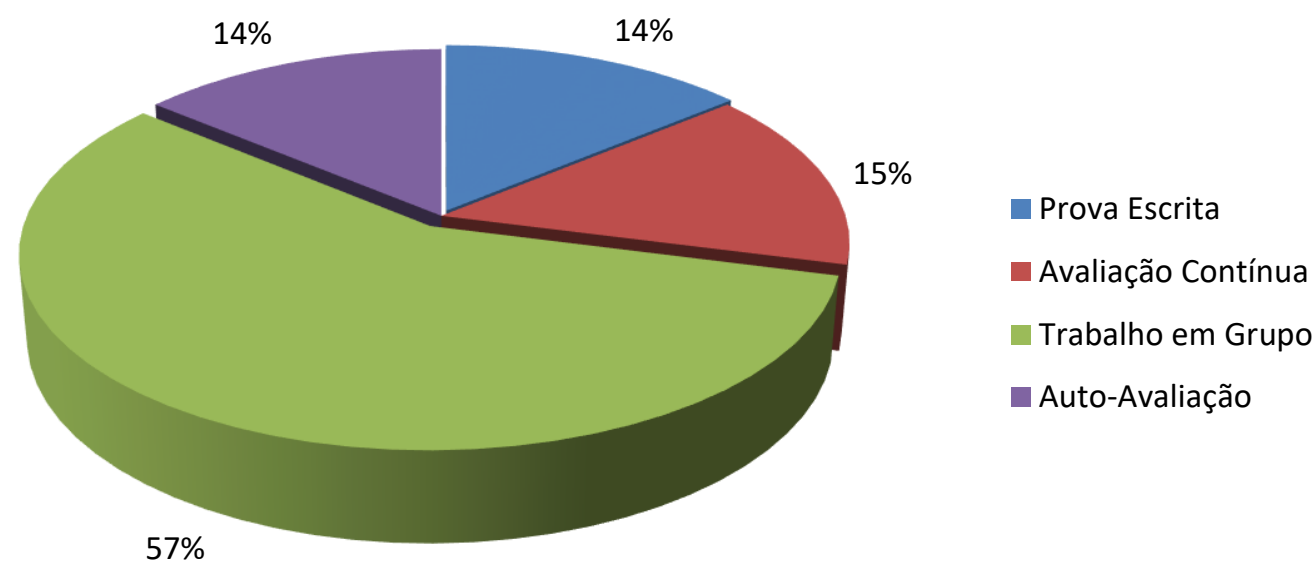

FONTE: Pesquisa de Campo (Set/2018)

De acordo com pesquisa realizada o que se entende é que os alunos desta turma não estão satisfeito com a forma de avaliação que a escola vem realizando suas atividades avaliativas, agora fica claro que os alunos não gostam de estudar ou algo parecido e preferem ser avaliado no trabalho coletivo.

Na escola “onde o foco é o conteúdo e não a aprendizagem, não há lugar para a diversidade". "O que existe é a adoção de um modelo de homem ideal, o qual todos devem corresponder, e um sistema de avaliação capaz de dizer quem está próximo e quem está distante desse modelo". Para este fim, utilizam-se desde testes padronizados e provas feitas pelo próprio professor até um conjunto de atividades avaliativas, as quais incluem questões orais, atividades em sala, tarefas de casa, entre outros, assim firma Freitas (2009).

O se observa hoje são vários fatores como: falha no sistema de educação, alguns professores mal humorados, sem motivação, sem planejamento, não tem compromisso com a educação. Assim, acredita-se que o educador pode continuar valendo-se de diferentes instrumentos avaliativos, deste que sob a perspectiva de discutir com os educando os resultados obtidos e utilizar a avaliação para melhorar as atividades de ensino-aprendizagem. 
Em contrapartida alunos desinteressado em aprender o conhecimento que é colocado pela grade curricular, a merenda na escola, principalmente nessa localidade, que geralmente não tem muita opção de cardápio, a maioria da merenda é arroz-doce, canjica, arroz com feijão, caracterizando vários fatores que levam os alunos por algum motivo não querer estudar além de tem muitas desculpas para não levar a sério a educação.

O objetivo desta pesquisa não é encontrar culpados, mas entender o que realmente acontece no processo avaliativo e o se pode fazer para tentar minimizar tal situação. A avaliação da aprendizagem esta interligada com a avaliação do desempenho e com a avaliação do currículo dentro do contexto escolar.

\section{RESULTADOS OBSERVADOS NA PESQUISA DE CAMPO EM LÓCUS COM OS ALUNOS SOBRE OS PROCESSOS DE AVALIAÇÃO NA ESCOLA PEQUENO POLEGAR.}

De acordo com a pesquisa feita com os alunos foi perguntado o seguinte: Qual é a maior dificuldade na hora de responder a prova? Do universo da pesquisa dos 105 alunos pesquisados $44 \%$ dos alunos têm dificuldade em interpretar o comando da prova, isso se torna complicado porque o aluno não consegue interpretar a questão, para os outros $35 \%$ dos pesquisados disseram que são muitas questões para serem respondidas, por isso eles não conseguem responder todas, já $21 \%$ dos pesquisados reclamam do tempo ser pouco para responder a prova.

Com base nestes pressupostos, pode-se afirmar que a realidade do processo avaliativo e completamente oposta à filosofia da educação que o sistema coloca para a escola como modelo de avaliação a ser seguido, problematizada à necessária em nossas escolas conhecer os conteúdos significa conhecer não apenas conceitos, definições ou fórmulas, mas também as relações que ligam esses conteúdos conceituais às experiências vividas pelos alunos em seu dia a dia.

Gráfico 02- Qual é a sua maior dificuldade na hora de responder a prova? 


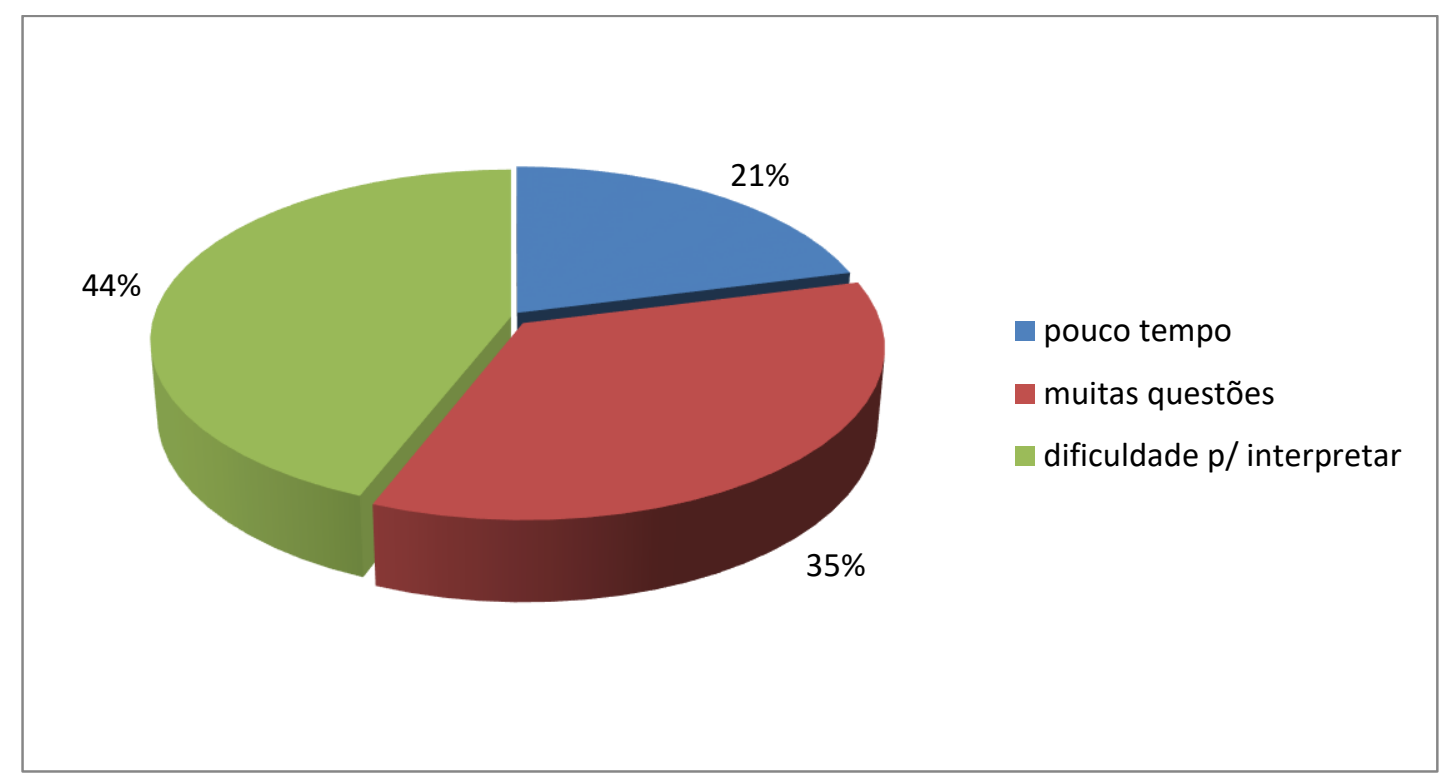

FONTE: Pesquisa de Campo (Set/2018)

No âmbito da pesquisa realizada com essa turma, o que se entende que os alunos a maioria tem dificuldade de interpretar o comando da questão a ser respondida, isso explica a dificuldade de alguns alunos de em relação à leitura no qual vimos anteriormente à falta de preparação dos alunos em dominar a leitura, os conhecimentos já concebidos diante da situação vimos que está faltando serem desenvolvidas as habilidades e competências dos educando, segundo Piaget a arte de perguntar com clareza e precisão se faz necessária e é importante que seja desenvolvida pelo professor no processo de sua interação com o aluno.

Analisando-se à ótica dos problemas que encontramos em sala de aula, muitos afirmam que essa seria uma visão utópica de educação, pois os alunos de hoje não se interessam, não tem responsabilidade, não querem aprender, não fazem nada em sala de aula.

Para o outro sujeitos da pesquisa disseram que são várias questões a serem respondidas, ás vezes, essa afirmação deve apontar o grau de despreparo do aluno para a interpretação da questão a ser concluída isso por que pode ser eles estão cansados ou com fome sem de falar na sala quente e cadeiras desconfortáveis tudo isso deixa o aluno desmotivado para enfrentar várias horas sentadas. Já o outro pesquisado que é a menor disseram que as provas são de poucas questões, esse índice indica que eles estão mais bem preparados para responder a prova. A prova pode e deve assumir a função de 
colaborar com o trabalho pedagógico, propiciando informações claras e precisas para o professor sobre a apropriação de saberes e o desenvolvimento do aluno.

A proposta construtivista busca indicar um caminho alternativo para uma nova relação no ensino, levando a uma aprendizagem eficaz em que os conhecimentos já adquiridos pelos alunos são fundamentais para a aprendizagem de novos conhecimentos. A partir de sua vivência o aluno constrói uma estrutura cognitiva formada por ideias e concepções ligadas ao senso comum do meio social em que está inserido e elabora representações em função das suas próprias experiências.

\section{CONSIDERACOES FINAIS}

Com esse trabalho procuramos demonstrar algumas concepções acerca da avaliação que foi de suma importância para o enriquecimento do nosso conhecimento, algo relevante para que professores e alunos possam refletir nos conceito dos autores e reformulação de seus próprios conceitos.

A busca por resposta a essas questões suscitam a necessidade do delineamento de objetivos que passou a orientar este trabalho acadêmico.

Nesse sentido, faz-se a necessidade de uma discussão sobre os fundamentos filosóficos que constituem fortemente as práticas avaliativas até hoje evidenciadas no fazer educativo. Sendo assim, o diálogo construído entre os teóricos da avaliação a partir dessa dimensão mais ampliada, se observa uma complexidade ainda maior a respeito do grande tema avaliação.

Entende-se que, por abarcar todo o fazer pedagógico, a avaliação não pode ser tratada de forma isolada.

Para enriquecer a pesquisa foram citados teóricos que descrevem suas concepções e experiência relatada em suas obras acerca da avaliação, pois a reflexão sobre os conceitos dos teóricos também possuem um papel muito importante, além disso, um bom profissional precisa agregar valores a sua prática profissional.

O desafio desta pesquisa é entender o processo de avaliação e como a mesma acontece no âmbito escolar, para o preparo do exercício da cidadania e sua qualificação para o trabalho. Na Educação Básica que, de acordo com o Art.22, o foco é desenvolver o educando, assegurar-lhe a formação comum indispensável para o exercício da cidadania, fornecer-lhe suporte e meios para progredir no trabalho e em estudos posteriores. 
O texto traz à tona a discussão sobre a avaliação escolar por ser um tema bastante polêmico e os mesmos mostram os novos sentidos da prática avaliativa nas escolas, orientações que vêm sendo sugeridas para a sua transformação da prática pedagógica de modo que como instrumento educacional seja inclusivo, formativo e pedagógico.

Por isso buscamos esses novos sentidos de orientações em propostas de alguns autores que discutem a questão da pesquisa e nas diretrizes nacionais educacionais atuais que organizam e revisam estruturas, estratégias e práticas educativas tais como: LDB, PCN'S, Conselhos Estaduais de Educação e as Diretrizes para Formação de Professores em suas atividades ativas, retratando, atualmente, a partir da ótica do tema da avaliação

\section{REFERÊNCIAS}

AFONSO, Andrade José AVALIAÇÃO EDUCACIONAL: regulação e emancipação para uma sociologia das políticas avaliativas contemporâneas. 3. Ed. São Paulo: Cortez, 2009.

ANTUNES, Celso. AVALIAÇÃO DA APRENDIZAGEM ESCOLAR:

FASCÍCULO 11. Petrópolis: Vozes, 2002.

ESTEBAN, Maria Tereza (org.) AVALIAÇÃO: UMA PRATICA EM BUSCA DE NOVOS SENTIDOS, Editora DPSA Rio de Janeiro, 2001.

ESTEBAN, Maria Tereza (org.) AVALIAÇÃo: UMA PRATICA EM BUSCA DE NOVOS SENTIDOS, Editora DPSA Rio de Janeiro, 2003.

GONÇALVES, Alba Lucia dissertação AVALIAÇÂO da APRENDIZAGEM Universidade Estadual de Santa Cruz UESC Ilhéus-BA, 2012.

JUSSARA, Hofmam AVALIAÇÃO MEDIADORA: UMA PRÁTICA EM CONSTRUÇÃO DA PRÉ-ESCOLA á universidade Editora mediação Porto Alegre, 2009.

LIBÂNEO, José Carlos, DIDÁTICA São Paulo Editora Cortez, 1994 
LUCKESI Carlos Cipriano AVALIAÇÃO DA APRENDIZAGEM ESCOLAR: Estudo e Proposição 22ªed. São Paulo, Cortez, 2011.

MAFFASIOLI, Luciana Gonçalves artigo AVALIAÇÃO DA APRENDIZAGEM NO PROEJA DO IFRS-BG: UMA ABORDAGEM FEITA A PARTIR DE SEUS SUJEITOS Universidade de Caxias do Sul RS, 2009.

RIBEIRO Mirian da Silva TCC AVALIAÇÃO DA APRENDIZAGEM NO ENSINO FUNDAMENTAL: NA PRÁTICA AVALIATIVA Universidade Estadual de Mato Grosso do Sul UEMGS 2010.

SAUL, Ana Maria. AVALIAÇÃO EMANCIPATÓRIA: DESAFIOS À TEORIA E À PRÁTICA DE AVALIAÇÃO E REFORMULAÇÃO DE CURRÍCULO. $7^{\circ}$ edição. São Paulo, SP: editora Cortez, 2006.

VASCONCELO, Celso dos Santos, AVALIAÇÃO: CONCEPÇÃO DIDÁTICA LIBERTADORA DO PROCESSODE AVALIAÇÃO ESCOLAR, Caderno Pedagógico da Liberdade, v. 3, 1998.

WEBER, Sonia Suzana Faria dissertação, AVALIAÇÂO DA APRENDIZAGEM ESCOLAR: PRÀTIA EM NOVAS PERSPECTIVAS Universidade Federal de Santa Maria UFSM RS, 2007. 